\title{
Oriented zinc oxide nanorods: A novel saturable absorber for lasers in the near-infrared
}

\author{
Pavel Loiko ${ }^{1}$, Tanujjal Bora ${ }^{2,3}$, Josep Maria Serres ${ }^{4}$, Haohai $\mathrm{Yu}^{5}$, Magdalena Aguiló ${ }^{4}$, \\ Francesc Díaz ${ }^{4}$, Uwe Griebner ${ }^{6}$, Valentin Petrov ${ }^{6}$, Xavier Mateos ${ }^{4}$ and Joydeep Dutta ${ }^{*}$
}

\author{
Full Research Paper \\ Address: \\ ${ }^{1}$ ITMO University, Kronverkskiy pr., 49, 197101 Saint-Petersburg, \\ Russia, ${ }^{2}$ Chair in Nanotechnology, Water Research Center, Sultan \\ Qaboos University, P.O. Box 17, Al-Khoudh, 123 Muscat, Oman, \\ ${ }^{3}$ Nanotechnology, School of Engineering and Technology, Asian \\ Institute of Technology, P.O. Box 4, Klong Luang, Pathumthani- \\ 12120, Thailand, ${ }^{4}$ Física i Cristallografia de Materials i Nanomaterials \\ (FiCMA-FiCNA)-EMaS, Dept. Química Física i Inòrganica, Universitat \\ Rovira i Virgili (URV), Campus Sescelades, 43007 Tarragona, Spain, \\ ${ }^{5}$ State Key Laboratory of Crystal Materials and Institute of Crystal \\ Materials, Shandong University, Jinan 250100, China, ${ }^{6}$ Max Born \\ Institute for Nonlinear Optics and Short Pulse Spectroscopy, \\ Max-Born-Str. 2a, 12489 Berlin, Germany and ${ }^{7}$ Functional Materials, \\ Applied Physics Department, School of Engineering Sciences, KTH \\ Royal Institute of Technology, Isafjordsgatan 22, SE-164 40 Kista \\ Stockholm, Sweden \\ Email: \\ Joydeep Dutta* - joydeep@kth.se \\ * Corresponding author \\ Keywords: \\ oriented nanorods; Q-switching; saturable absorption; solid-state \\ lasers; zinc oxide \\ Beilstein J. Nanotechnol. 2018, 9, 2730-2740. \\ doi:10.3762/bjnano.9.255 \\ Received: 22 May 2018 \\ Accepted: 28 September 2018 \\ Published: 23 October 2018 \\ Associate Editor: E. Meyer \\ (C) 2018 Loiko et al.; licensee Beilstein-Institut. \\ License and terms: see end of document.
}

\begin{abstract}
Zinc oxide $(\mathrm{ZnO})$ nanorods $(\mathrm{NRs})$ oriented along the crystallographic [001] axis are grown by the hydrothermal method on glass substrates. The $\mathrm{ZnO}$ NRs exhibit a broadband (1-2 $\mu \mathrm{m})$ near-IR absorption ascribed to the singly charged zinc vacancy $\mathrm{V}_{\mathrm{Zn}}{ }^{-1}$. The saturable absorption of the $\mathrm{ZnO}$ NRs is studied at $\approx 1 \mu \mathrm{m}$ under picosecond excitation, revealing a low saturation intensity, $\approx 10 \mathrm{~kW} / \mathrm{cm}^{2}$, and high fraction of the saturable losses. The ZnO NRs are applied as saturable absorbers in diode-pumped $\mathrm{Yb}(\approx 1.03 \mu \mathrm{m})$ and $\mathrm{Tm}(\approx 1.94 \mu \mathrm{m})$ lasers generating nanosecond pulses. The ZnO NRs grown on various optical surfaces are promising broadband saturable absorbers for nanosecond near-IR lasers in bulk and waveguide geometries.
\end{abstract}

\section{Introduction}

Zinc oxide $(\mathrm{ZnO})$ is a well-known II-IV group wide-bandgap semiconductor $\left(E_{\mathrm{g}}=3.37 \mathrm{eV}\right)$, possessing a hexagonal wurtzitetype (sp. gr. $\left.P 6_{3} m c\right)$ structure with unit cell parameters $a=3.25 \AA, c=5.20 \AA$. In recent years, a lot of attention has been paid to the studies of $\mathrm{ZnO}$ nanostructures of various shapes, including oriented nanorods (NRs), nanowires, 
nanobelts, nanoparticles, etc. for versatile photonic applications $[1,2]$. ZnO NRs are especially attractive for short-wavelength nano-devices due to their high exciton binding energy $(60 \mathrm{meV})$ [3], allowing for efficient excitonic photoluminescence at room temperature, and due to their good mechanical and thermal stability. Arrays of $\mathrm{ZnO}$ NRs can be grown on various substrates (e.g., $\mathrm{Si}, \mathrm{Al}_{2} \mathrm{O}_{3}$, glass) either by gas phase processes (e.g., by vapor-liquid-solid epitaxy, metal-organic chemical vapor deposition, pulsed laser deposition), or by wet-chemical processes (e.g., the hydrothermal method, electrochemical deposition) [4]. The hydrothermal growth of $\mathrm{ZnO}$ NRs is a relatively simple, versatile and low temperature process [5]. ZnO NRs are used in gas sensors due to the high sensitivity of $\mathrm{ZnO}$ to chemical environments [6], for light-emitting diodes due to the compatibility with the GaN technology and random lasing [7] (in the blue, around $0.390 \mu \mathrm{m}$ ), and in dye-sensitized solar cells [8].

The absorption and emission properties of the $\mathrm{ZnO}$ nanomaterials are physically related to the defects in the $\mathrm{ZnO}$ structure [9]. This is due to the relatively open structure of $\mathrm{ZnO}$ where the $\mathrm{Zn}^{2+}$ ions occupy half of the tetrahedral $\left(T_{\mathrm{d}}\right)$ sites and all the octahedral $\left(O_{\mathrm{h}}\right)$ ones are empty. The structure of $\mathrm{ZnO}$ is determined by alternating planes of tetrahedrally coordinated $\mathrm{Zn}^{2+}$ and $\mathrm{O}^{2-}$ ions stacked along the [001]-axis. Thus, there are many options to accommodate intrinsic defects (e.g., interstitial $\mathrm{Zn}^{2+}$ ions, $\mathrm{Zn}_{\mathrm{i}}$, or $\mathrm{O}^{2-}$ vacancies, $\mathrm{V}_{\mathrm{O}}$, which are the most widespread ones), as well as external dopants (e.g., divalent transition-metal ions $\mathrm{M}^{2+}$ entering into the $T_{\mathrm{d}}$ sites, where $\mathrm{M}=\mathrm{Co}$, $\mathrm{Mn}, \mathrm{Ni}$ or $\mathrm{Cu}$ ). The energy levels of the intrinsic defects are located between the valence and conduction bands and have different ionization energies ranging from $\approx 0.05$ to $2.8 \mathrm{eV}$ [10]. Various emissions (fluorescence) in the visible (green, yellow and red) originating from the defects in $\mathrm{ZnO}$ have been demonstrated [11].

Such properties of $\mathrm{ZnO}$ NRs make them interesting for potential applications in lasers. Recently, a number of nanostructures exhibiting broadband linear absorption (from the visible to near-IR) and ultrafast and broadband saturable absorption have been proposed as "fast" saturable absorbers (SAs) for lasers operating in the passively Q-switched (PQS) and mode-locked regimes. These include carbon nanostructures (e.g., graphene, graphene oxide, graphite nanoparticles, single-walled carbon nanotubes (SWCNTs)) [12-15], few-layer transition metal dichalcogenides (TMDs, e.g., $\mathrm{MoS}_{2}$, $\mathrm{WS}_{2}[16,17]$, black phosphorus (BP) [18]), and topological insulators (TIs, e.g., $\mathrm{Bi}_{2} \mathrm{Te}_{3}, \mathrm{Sb}_{2} \mathrm{Te}_{3}$ [19,20], graphitic carbon nitride $\left.\left(\mathrm{g}-\mathrm{C}_{3} \mathrm{~N}_{4}\right)[21]\right)$. In the PQS regime, such structures enable the generation of nanosecond pulses at high repetition rates (up to $\mathrm{MHz}$ ) and they are attractive for compact laser designs (e.g., microchip or waveguide lasers) [22].

ZnO NRs have not been explored as saturable absorbers, yet. Singh et al. studied $\mathrm{Mn}^{2+}$-doped $\mathrm{ZnO}$ NRs grown from an aqueous solution on indium tin oxide (ITO) substrates which exhibited saturable absorption (optical bleaching) at $0.532 \mu \mathrm{m}$ under ns-laser excitation [23]. This effect was ascribed to the defects promoted by the $\mathrm{Mn}^{2+}$ doping. Some studies revealed reverse saturable absorption (optical limiting) in $\mathrm{ZnO}$ thin films and NRs [24]. Zhu et al. studied ultrafast saturable absorption of multiwalled carbon nanotubes (MWCNTs) on quartz substrates beaded with $\mathrm{ZnO}$ nanoparticles [25]. This effect was demonstrated at $0.780 \mu \mathrm{m}$ with femtosecond pulses. Ahmad et al. employed $\mathrm{ZnO}$ nanoparticles in a polymer thin film as a SA for an Er fiber laser. The absorption saturation experiment performed at $1.560 \mu \mathrm{m}$ revealed a saturation intensity as low as $16 \mathrm{~kW} / \mathrm{cm}^{2}$ for this material [26]. Loiko et al. studied the saturable absorption of $\mathrm{Co}^{2+}$-doped $\mathrm{ZnO}$ nanocrystals in a glass matrix at $1.540 \mu \mathrm{m}$, employing them as a SA for a bulk Er laser [27], however, the saturable absorption was mostly due to the $\mathrm{Co}^{2+}$ ions in $T_{\mathrm{d}}$ sites.

In the present work, we demonstrate the suitability of hydrothermally grown, oriented $\mathrm{ZnO}$ NRs as SAs for lasers emitting at 1 and $2 \mu \mathrm{m}$, for the first time, to the best of our knowledge. The preliminary results of this work were presented in a conference paper [28].

\section{Results and Discussion \\ Structural study}

Figure 1 shows the field emission scanning electron microscope (FESEM) micrographs of the $\mathrm{ZnO}$ NRs grown hydrothermally for $5 \mathrm{~h}, 10 \mathrm{~h}$ and $15 \mathrm{~h}$. The average length and diameter of the NRs were found to increase with the growth time, as summarized in Table 1. All ZnO NRs showed a characteristic hexagonal shape with orientation almost perpendicular to the glass substrate. In the initial growth periods, Ostwald ripening competes with the growth and results in merging of thinner NRs with thicker ones. With time, this process saturates and the growth continues. This is the reason why the growth of the NRs is not linear at the early stage of the process.

Figure 2a shows typical XRD patterns of the ZnO NRs grown for 5-15 h. All ZnO samples showed characteristic XRD peaks (verified from JCPDS card No. 01-070-8070) confirming the hexagonal wurtzite structure (sp. gr. $P 6_{3} m c$ ). The strongest XRD peak observed at $34.35^{\circ}$ indicated the preferential orientation of the nanorods along the [001] crystallographic axis. No notable variation in the XRD patterns of the NRs was observed with respect to growth time. 


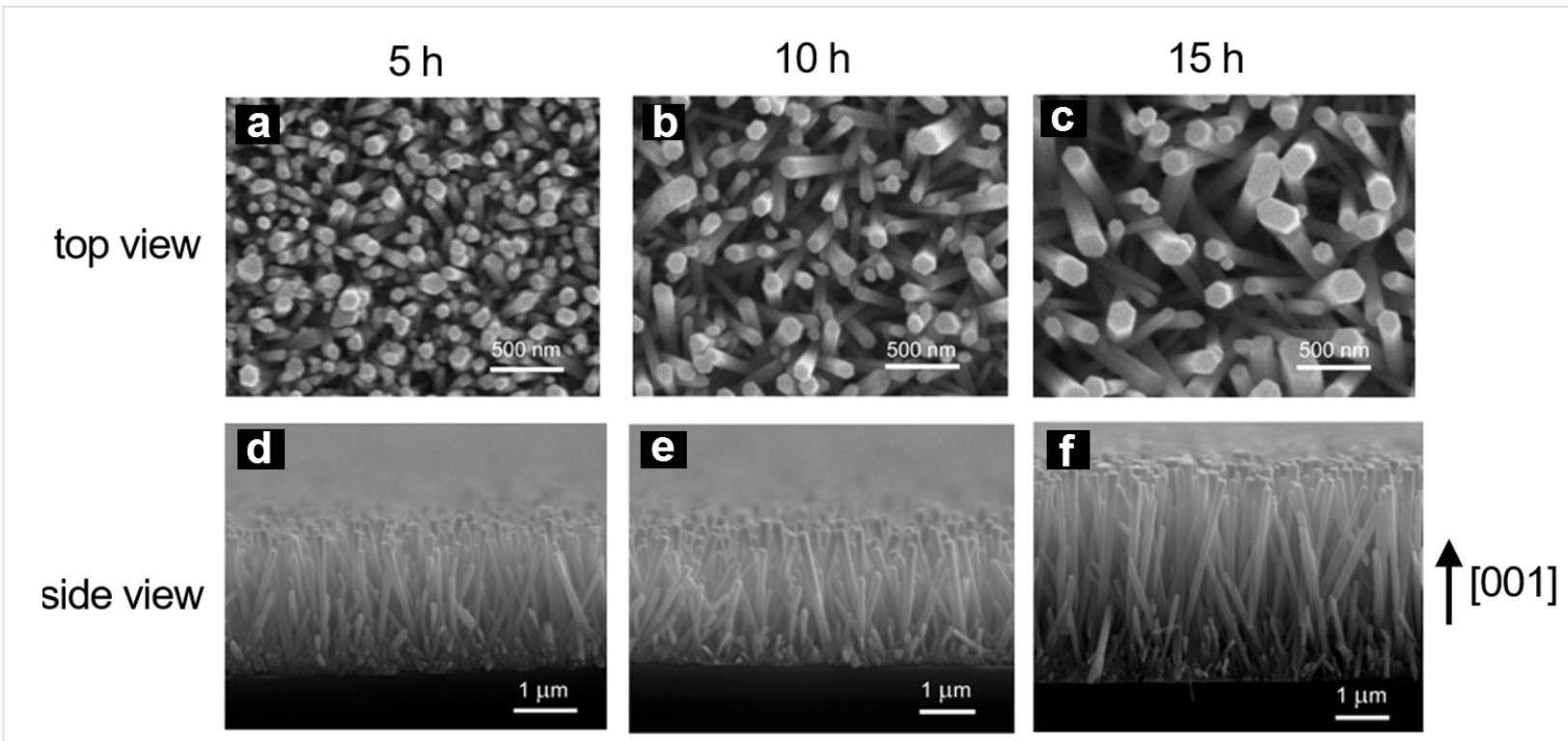

Figure 1: Field emission scanning electron microscope (FESEM) images of ZnO nanorods grown hydrothermally on glass substrates for (a,d) $5 \mathrm{~h}$, (b,e) $10 \mathrm{~h}$ and (c,f) $15 \mathrm{~h} ;(\mathrm{a}, \mathrm{b}, \mathrm{c})$ top- and (d,e,f) side-view. Images (b) and (e) are reproduced with permission from [28], copyright 2017, IEEE.

Table 1: Dimensions of the $\mathrm{ZnO}$ nanorods.

\begin{tabular}{ccc} 
growth time $(\mathrm{h})$ & avg. length $(\mu \mathrm{m})$ & avg. diameter $(\mathrm{nm})$ \\
\hline 5 & $2.1 \pm 0.2$ & $80 \pm 20$ \\
10 & $2.4 \pm 0.1$ & $100 \pm 25$ \\
15 & $3.5 \pm 0.2$ & $160 \pm 25$
\end{tabular}

The Raman spectra of the ZnO NRs are shown in Figure $2 b$, where a strong Raman scattering at $435 \mathrm{~cm}^{-1}$ representing the $E_{2}{ }^{\text {high }}$ phonon mode of $\mathrm{ZnO}$ is seen along with a broad peak centered around $574 \mathrm{~cm}^{-1}$ representing the $A_{1}(\mathrm{LO})$ mode [29]. All samples showed almost identical Raman spectra irrespective of their growth times or sizes. A schematic of the shape of
$\mathrm{ZnO}$ NRs is shown in Figure 2c where the growth direction is indicated.

\section{Linear optical spectroscopy}

The results on the optical absorption and luminescence of the $\mathrm{ZnO} \mathrm{NRs}$ are summarized in Figure 3. The small-signal (internal) absorption spectra of the ZnO NRs grown for 5-15 h are shown in Figure 3a. The spectra were corrected for the Fresnel losses arising from the substrate, $T(\mathrm{ZnO} N R s)=T(\mathrm{ZnO}$ NRs + substrate) $/ T$ (substrate), where $T$ is the measured transmission. With the increase of the growth duration, the transmission of the $\mathrm{ZnO}$ NRs decreases. Moreover, the scattering losses become more evident, as observed by the fast decrease of the transmission at wavelengths $<1 \mu \mathrm{m}$, see also Figure $3 \mathrm{~b}$. Here, the scattering was modelled with an empirical formula (scat-
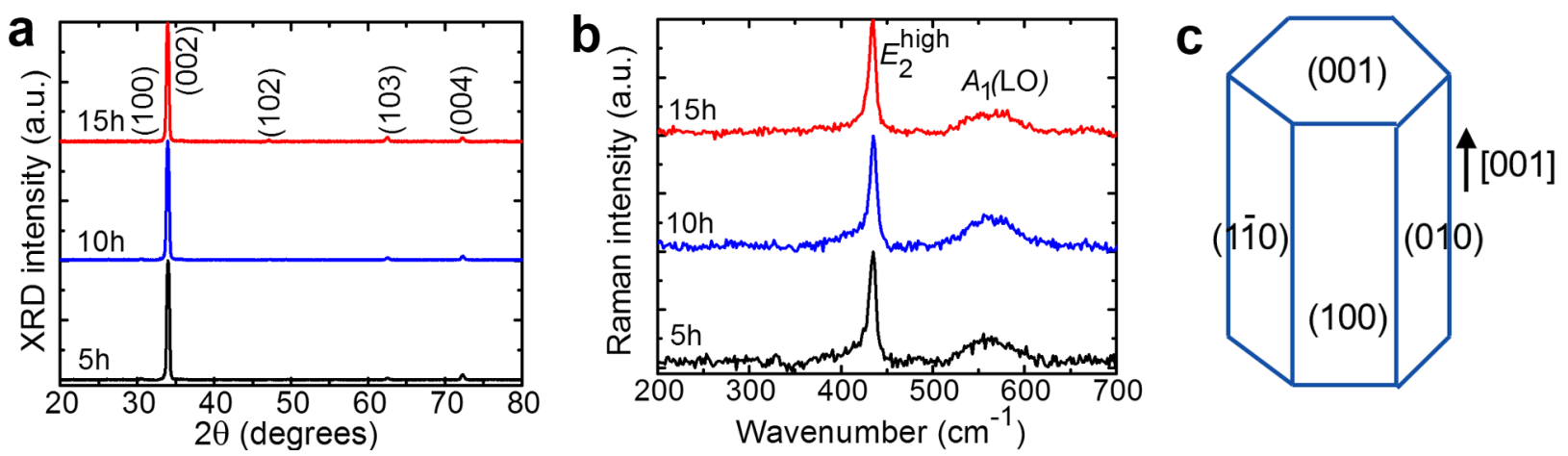

Figure 2: (a) X-ray diffraction (XRD) patterns and (b) Raman spectra measured with an excitation wavelength of $0.532 \mu \mathrm{m}$ of $\mathrm{ZnO} N R \mathrm{~s}$ grown hydrothermally on glass substrates for 5-15 h; (c) schematic of the NR shape. The data for $10 \mathrm{~h}$ growth duration are adapted from [28]. 

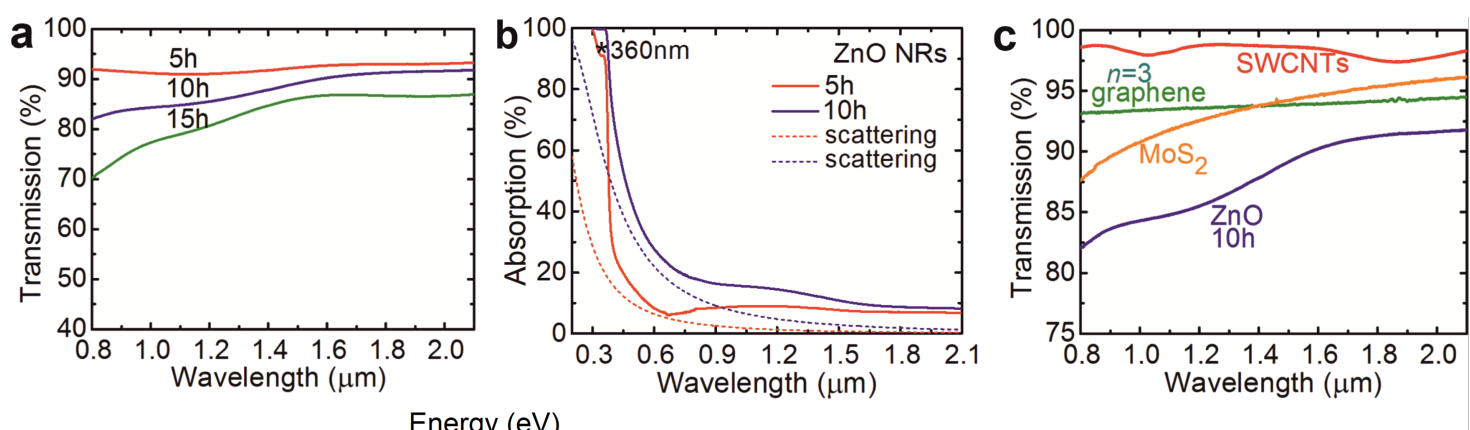

Energy (eV)

$3.102 .762 .48 \quad 2.252 .071 .91$
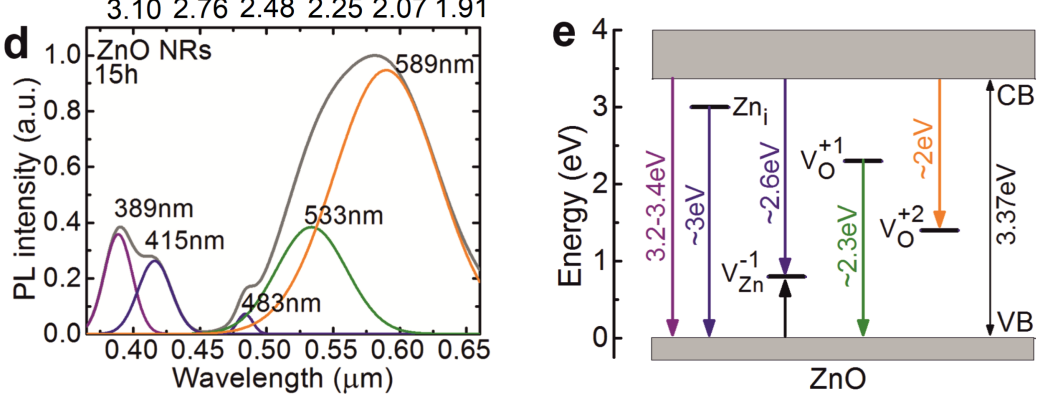

Figure 3: (a) Small-signal absorption spectra of the ZnO NRs grown hydrothermally on glass substrates for $5-15 \mathrm{~h}, T(\mathrm{ZnO} N R s)=T(\mathrm{ZnO} N R s+$ substrate)/T(substrate); (b) estimation of the scattering losses in ZnO NRs grown for $5 \mathrm{~h}$ and $10 \mathrm{~h}$ (dashed curves); (c) comparison of the small-signal

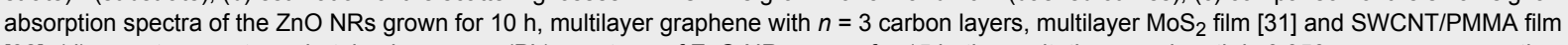
[32]; (d) room temperature photoluminescence $(\mathrm{PL})$ spectrum of ZnO NRs grown for $15 \mathrm{~h}$, the excitation wavelength is $0.350 \mu \mathrm{m}$ : grey curve - the measured PL spectrum, color bands - decomposition of the PL spectrum into Gaussian components; (e) scheme of the defect states in the bandgap of $\mathrm{ZnO}$ (the color of arrows corresponds to the color of the emission bands in (d).

tering loss $\approx \lambda^{-2.35}$ ) [30]. The $\mathrm{ZnO}$ NRs are characterized by a broadband near-IR absorption featuring two broad bands centered at $\approx 1.2$ and $\approx 2 \mu \mathrm{m}$, Figure $3 \mathrm{a}$.

Let us discuss the nature of the broadband optical absorption of $\mathrm{ZnO}$ NRs. In Figure $3 \mathrm{~b}$ for the NRs grown for $5 \mathrm{~h}$, a characteristic absorption peak at $\approx 360 \mathrm{~nm}$ is observed (as indicated by an asterisk). This absorption peak is related to direct band-to-band transitions and its position is notably blue-shifted with respect to bulk $\mathrm{ZnO}$ due to the nanometer size effect. As the $\mathrm{ZnO}$ NRs were grown hydrothermally (in oxygen-rich conditions) one can expect the presence of zinc vacancies that have a low formation energy under such conditions. The singly charged zinc vacancy $\left(\mathrm{V}_{\mathrm{Zn}}{ }^{-1}\right)$ is typically located at $0.8-0.9 \mathrm{eV}$ above the $\mathrm{ZnO}$ valence band (VB) $[9,33,34]$. This defect site can be a possible source for the near-IR absorption. For longer NRs, one can expect more $\mathrm{V}_{\mathrm{Zn}}{ }^{-1}$ vacancies and stronger near-IR absorption, in agreement with Figure 3a.

In Figure 3c, we compare the small-signal absorption spectra of $\mathrm{ZnO}$ NRs grown for $10 \mathrm{~h}$ and several well-known nanostructured "fast" SAs, namely a commercial graphene-SA containing several $(n=3)$ carbon layers, a SA based on randomly oriented SWCNTs in a PMMA film [32], and a few-layer $\mathrm{MoS}_{2}$
SA [31]. One can observe a similar broadband absorption feature for the $\mathrm{ZnO}$ NRs as in these reference SAs.

The photoluminescence (PL) spectrum of $\mathrm{ZnO}$ NRs grown for $15 \mathrm{~h}$ is shown in Figure $3 \mathrm{~d}$. The excitation wavelength was $0.350 \mu \mathrm{m}$. The PL spectrum is composed of five major PL bands peaking at around $0.389,0.415,0.483,0.533$ and $0.589 \mu \mathrm{m}$.

The assignment of the PL bands of $\mathrm{ZnO}$ NRs is as follows. The band at $0.389 \mu \mathrm{m}$ can be assigned to the direct recombination of electrons from the conduction band (CB) to the $\mathrm{VB}$ of $\mathrm{ZnO}$ (band-to-band transition). The violet emission near $0.415 \mu \mathrm{m}$ can be assigned to the radiative recombination of electrons from a zinc interstitial $\left(\mathrm{Zn}_{\mathrm{i}}\right)$ defect level, typically located $\approx 0.22 \mathrm{eV}$ below the $\mathrm{CB}$, to the $\mathrm{VB}$ of $\mathrm{ZnO}$ [35]. The PL band at $0.483 \mu \mathrm{m}$ is due to the radiative capture of an electron from the $\mathrm{CB}$ by a zinc vacancy state $\left(\mathrm{V}_{\mathrm{Zn}}{ }^{-1}\right)$ located around $0.8-0.9 \mathrm{eV}$ above the $\mathrm{VB}$ of $\mathrm{ZnO}[9,33,34]$. The broad green-yellow luminescence from the $\mathrm{ZnO} \mathrm{NRs}$ is composed of two bands peaking at 0.533 and $0.589 \mu \mathrm{m}$. These bands are assigned to the singly $\left(\mathrm{V}_{\mathrm{O}}{ }^{+1}\right)$ and doubly charged $\left(\mathrm{V}_{\mathrm{O}}{ }^{+2}\right)$ oxygen vacancy states of $\mathrm{ZnO}$, respectively [36-38]. Based on these assignments, a schematic diagram showing the position of the various defect states within 
the bandgap of $\mathrm{ZnO}$ and the corresponding PL lines is presented in Figure 3e.

\section{Absorption saturation}

The measured open-aperture $\mathrm{Z}$-scan curve for the $\mathrm{ZnO}$ NRs grown for $10 \mathrm{~h}$ is shown in Figure $4 \mathrm{a}$. It was fitted according to the formula $\alpha^{\prime}(I)=\alpha_{\mathrm{NS}}^{\prime}+\alpha_{\mathrm{S}}^{\prime} /\left(1+I / I_{\text {sat }}\right)$, where $\alpha^{\prime}=1-T$ is the sample absorption (Fresnel losses were subtracted), $I$ is the light intensity, $\alpha_{\mathrm{NS}}^{\prime}$ and $\alpha_{\mathrm{S}}^{\prime}$ is the non-saturable and saturable absorption, respectively, and $I_{\text {sat }}$ is the saturation intensity. In the small-signal regime $(I \approx 0)$ the absorption is, $\alpha_{0}^{\prime}=\alpha_{\mathrm{NS}}^{\prime}+\alpha_{\mathrm{S}}^{\prime}=$ $1-T_{0}$. There are thus two free parameters, $\alpha_{\text {NS }}^{\prime}$ and $I_{\text {sat }}$. The spatial and temporal distribution of the laser intensity on the sample were accounted for [31]. Figure $4 \mathrm{~b}$ shows the absorption saturation curve for the $\mathrm{ZnO}$ NRs plotted vs the peak on-axis laser intensity, $I_{0}=2 E /\left(\pi w_{\mathrm{L}}^{2} \Delta \tau^{*}\right)$, where $\Delta \tau^{*} \approx 1.06 \Delta \tau$.

The absorption saturation curves for the $\mathrm{ZnO}$ NRs grown for 5-15 $\mathrm{h}$ are compared in Figure 4c. The corresponding absorption saturation parameters are listed in Table 2.

Now let us discuss the absorption saturation of $\mathrm{ZnO}$ NRs. With the increase of the growth duration from 5 to $15 \mathrm{~h}, I_{\text {sat }}$ decreases from 13 to $9 \mathrm{~kW} / \mathrm{cm}^{2}$; the saturable absorption $\alpha_{\mathrm{S}}^{\prime}$ also increases from $2.2 \%$ to $9.7 \%$. Moreover, the fraction of the saturable losses, $\alpha_{S}^{\prime} / \alpha_{0}^{\prime}$, increases from 0.25 to 0.42 . This effect is assigned to the increased diameter of the NRs and their crystallinity and weaker boundary effects. The non-saturable losses of the $\mathrm{ZnO}$ NRs can be partially attributed to the scattering losses. It should be noted that the observed values of $I_{\text {sat }}$ for the $\mathrm{ZnO}$ NRs are much lower compared, e.g., with the few-layer $\mathrm{MoS}_{2} \mathrm{SA}\left(0.5 \mathrm{MW} / \mathrm{cm}^{2}\right)$ [31] which can be due to the at least partial coupling of light inside the NRs thus enhancing the light-matter interaction. Previously, the absorption saturation of $\mathrm{ZnO}$ nanocrystals in a polymer film was studied [26] at $1.560 \mu \mathrm{m}$ also with picosecond pulses resulting in $I_{\text {sat }}=16 \mathrm{~kW} / \mathrm{cm}^{2}$, which is close to our observations.
Table 2: Absorption saturation properties of the $\mathrm{ZnO}$ nanorods.

\begin{tabular}{ccccc}
$T(\mathrm{~h})^{\mathrm{a}}$ & $I_{\text {sat }}, \mathrm{kW} / \mathrm{cm}^{2}$ & $\alpha_{0}^{\prime}$ & $\alpha_{\mathrm{S}}^{\prime}$ & $\alpha_{\mathrm{S}}^{\prime} / \alpha_{0}^{\prime}$ \\
\hline 5 & 13 & $8.7 \%$ & $2.2 \%$ & 0.25 \\
10 & 10 & $16.3 \%$ & $5.7 \%$ & 0.35 \\
15 & 9 & $23.0 \%$ & $9.7 \%$ & 0.42 \\
\hline
\end{tabular}

aGrowth time.

\section{Passive Q-switching by $\mathrm{ZnO}$ nanorods}

The laser experiments were performed with the NRs grown for $5 \mathrm{~h}$, because they exhibited minimum insertion loss. Stable Q-switching was also observed for the NRs grown for $10 \mathrm{~h}$, though the pulse characteristics were inferior. The experiments were performed in a microchip-type laser cavity in order to shorten the laser pulses due to the reduced cavity roundtrip time.

The performance of the Tm:KLuW laser PQS by the ZnO NRs was studied first. This laser generated a maximum average output power of $221 \mathrm{~mW}$ at $1.942 \mu \mathrm{m}$ with a slope efficiency $\eta$ of $10 \%$ (with respect to the absorbed pump power $P_{\mathrm{abs}}$ ), see Figure 5a,b. The laser threshold was at $P_{\mathrm{abs}}=1.05 \mathrm{~W}$. In the $\mathrm{CW}$ regime, the laser operated with higher efficiency, $\eta$ of $56 \%$ and lower laser threshold of $0.70 \mathrm{~W}$, so that the conversion efficiency with respect to the $\mathrm{CW}$ mode, $\eta_{\text {conv }}$, was only $16 \%$ mostly due to the insertion losses of the SA. The emission spectrum of the CW laser consisted of several peaks in the spectral range $1.936-1.951 \mu \mathrm{m}$. These results correspond to the optimum transmission of the output coupler, $T_{\mathrm{OC}}$, of $5 \%$. Power scaling of the laser in the PQS regime was limited by the Q-switching instabilities arising for $P_{\mathrm{abs}}>3.2 \mathrm{~W}$ due to the heating of the SA by the residual (non-absorbed) pump [22].

The pulse duration $\Delta \tau$, determined as full width at half maximum (FWHM) and the pulse repetition frequency (PRF)
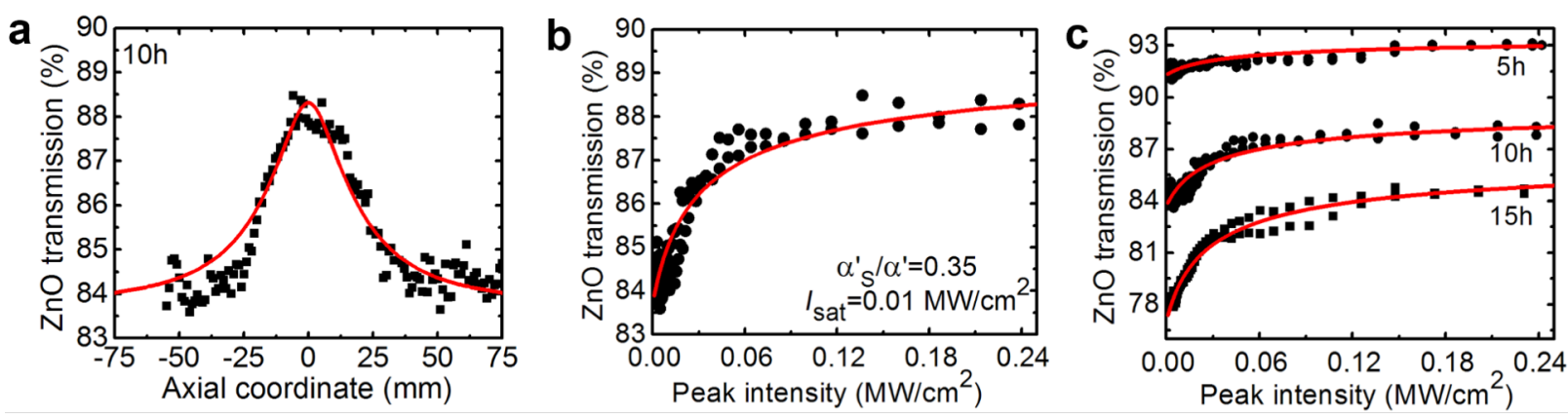

Figure 4: Absorption saturation of ZnO nanorods (NRs): (a,b) NRs grown for $10 \mathrm{~h}$, (a) open-aperture Z-scan experiment and (b) the corresponding absorption saturation curve (measured at $1.06 \mu \mathrm{m}$ under ps excitation), points - experimental data, red curve - fitting; (c) comparison of the absorption saturation curves for NRs grown for 5-15 $\mathrm{h}$. The data plotted in (b) are adapted from [28]. 

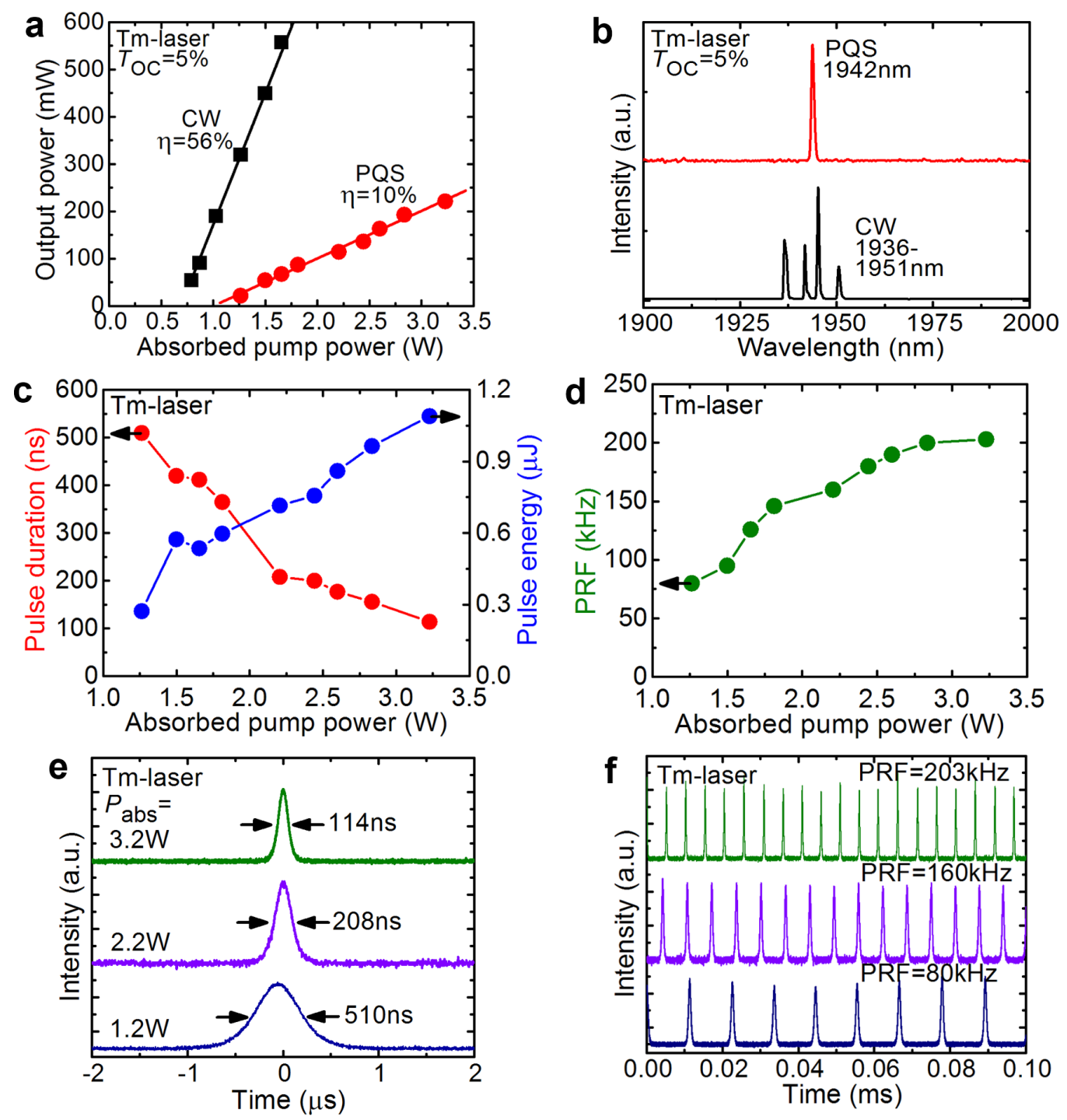

Figure 5: Tm:KLuW laser: CW operation and passive Q-switching by ZnO NRs grown for $5 \mathrm{~h}$ : (a) input-output dependences, $\eta$ - slope efficiency (the data for PQS operation are adapted from [28]); (b) typical laser emission spectra measured at the maximum $P_{\text {abs; }}$ (c) pulse duration and pulse energy, adapted from [28]; (d) pulse repetition frequency (PRF); (e,f) typical oscilloscope traces of (e) single Q-switched pulses and (f) the corresponding pulse trains for different $P_{\text {abs }}$ (the pulse train corresponding to a PRF of $203 \mathrm{kHz}$ is adapted from [28]).

for the PQS laser were measured directly. The pulse energy $E_{\text {out }}$ was then calculated as $P_{\text {out }} / \mathrm{PRF}$. These pulse characteristics for the Tm laser are plotted in Figure 5c,d. They show a notable dependence on the absorbed pump power, as expected for "fast" SAs. Indeed, $\Delta \tau$ decreases from 510 to $114 \mathrm{~ns}$, while PRF increases from 80 to $203 \mathrm{kHz}$ and $E_{\text {out }}$ - from 0.3 to $1.1 \mu \mathrm{J}$. Such a behavior is related to the increasing intracavity laser intensity on the SA and its effect on the SA dynamic bleaching [39]. The dependence of the pulse characteristics on $P_{\mathrm{abs}}$ is also illustrated in Figure 5e,f showing oscilloscope traces of single Q-switched pulses and the corresponding pulse trains. The single pulses have a nearly Gaussian temporal shape. The intensity instabilities in the pulse trains are $<10 \%$.
A similar experiment was performed for the $\mathrm{Yb}: \mathrm{KLuW}$ laser, Figure 6. In the PQS regime, this laser generated a maximum average output power of $139 \mathrm{~mW}$ at $1.034 \mu \mathrm{m}$ with $\eta=9 \%$, as shown in Figure 6a,b. The laser threshold was at $P_{\mathrm{abs}}=1.90 \mathrm{~W}$. In the $\mathrm{CW}$ regime, the laser operated with higher $\eta$ of $66 \%$ and $\eta_{\text {conv }}$ was $14 \%$. In the $\mathrm{CW}$ regime, a multi-peak emission at $1.035-1.040 \mu \mathrm{m}$ was observed. These results correspond to the optimum $T_{\mathrm{OC}}$ of $10 \%$. The Q-switching instabilities were detected for $P_{\mathrm{abs}}>3.3 \mathrm{~W}$.

The pulse characteristics of the Yb:KLuW laser PQS by ZnO NRs (duration $\Delta \tau$, PRF and energy $E_{\text {out }}$ ), the oscilloscope traces of single Q-switched pulses and the corresponding pulse trains 

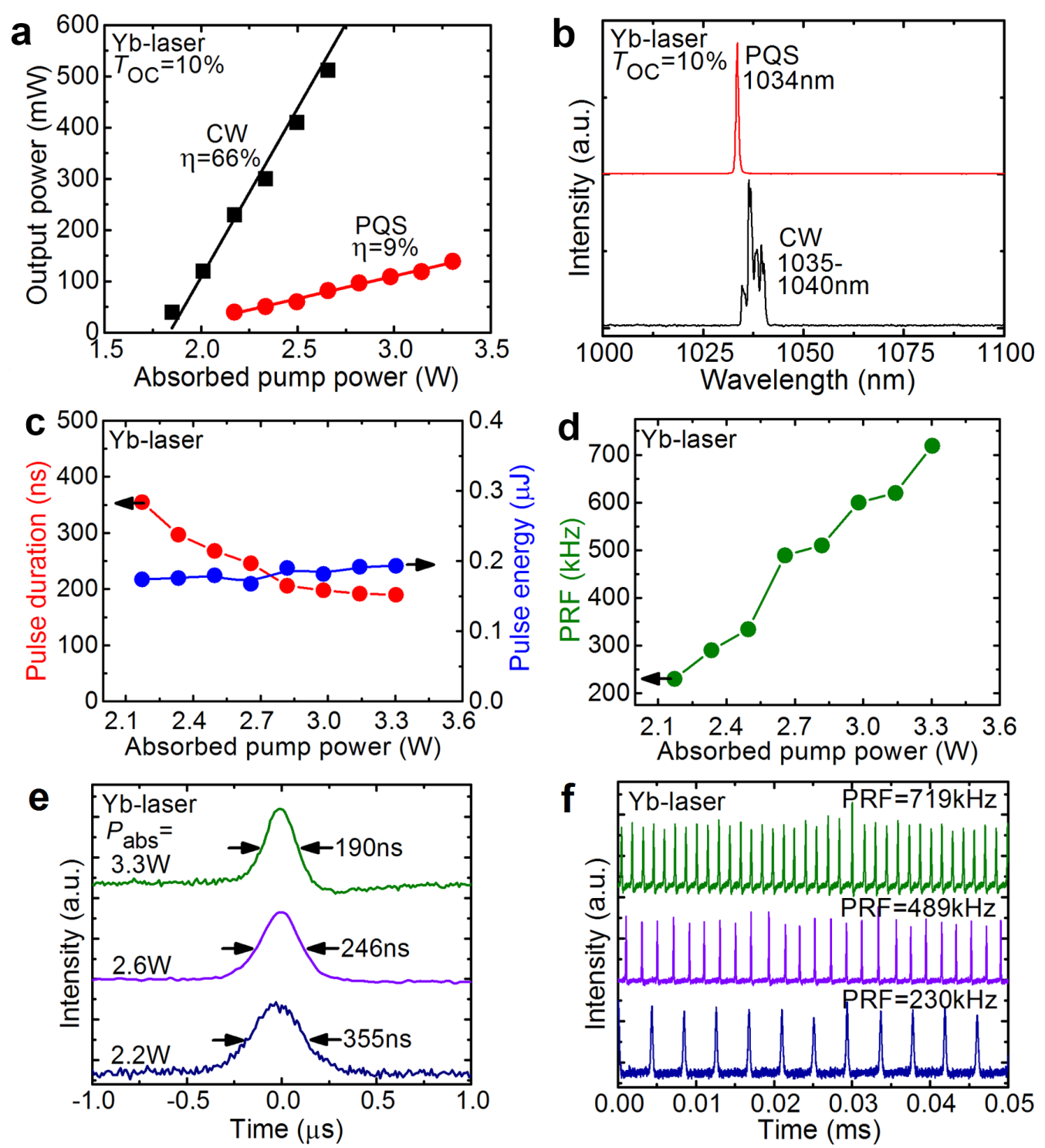

Figure 6: Yb:KLuW laser: CW operation and passive Q-switching by ZnO nanorods grown for $5 \mathrm{~h}$ : (a) input-output dependences, $\eta$ - slope efficiency (the data for PQS operation are adapted from [28]); (b) typical laser emission spectra measured at the maximum $P_{\text {abs; }}$ (c) pulse duration and pulse energy; (d) pulse repetition frequency (PRF); (e,f) typical oscilloscope traces: (e) single Q-switched pulses and (f) the corresponding pulse trains for various $P_{\text {abs }}$ (the pulse train corresponding to a PRF of $719 \mathrm{kHz}$ is adapted from [28]).

can be found in Figure $6 \mathrm{c}-\mathrm{f}$. With the increase of the absorbed pump power, the pulse duration decreases from 355 to $190 \mathrm{~ns}$, the PRF increases from 230 to $719 \mathrm{kHz}$ and the pulse energy was found to be weakly dependent on $P_{\text {abs }}$ and amounted to $\approx 0.2 \mu \mathrm{J}$. The pulse trains, Figure $6 \mathrm{e}, \mathrm{f}$, exhibit stronger intensity instabilities than those for the Tm laser.

\section{Comparison of $\mathrm{ZnO}$ NRs with nanostructured SAs}

In Table 3, we compare the output characteristics of $\mathrm{Yb}: \mathrm{KLuW}$ and Tm:KLuW lasers PQS by various "fast" SAs reported in the literature. These are graphene-SA based on single $(n=1)$ and several $(n=3)$ stacked carbon layers, few-layer $\mathrm{MoS}_{2} \mathrm{SA}$, a SA based on randomly oriented SWCNTs in a PMMA film (all of them deposited on a $1 \mathrm{~mm}$-thick fused silica substrate), and a commercial transmission-type semiconductor saturable absorber (SESA, for Tm laser). For the $\mathrm{Yb}$ laser, the performance of all such nanostructured SAs is modest. In general, this is related to higher scattering losses in such SAs at $\approx 1 \mu \mathrm{m}$, as well as higher saturation intensities of such materials for higher photon energies. ZnO NRs are slightly better than such 2D materials as graphene-SA with a single carbon layer and few-layer $\mathrm{MoS}_{2}$. However, their performance is inferior as compared to the 


\begin{tabular}{|c|c|c|c|c|c|c|c|}
\hline laser & SA & $P_{\text {out }}, \mathrm{mW}$ & $\eta, \%$ & $E_{\text {out }}, \mu \mathrm{J}$ & $\Delta \mathrm{T}, \mathrm{ns}$ & $\mathrm{PRF}, \mathrm{kHz}$ & ref. \\
\hline \multirow[t]{5}{*}{ Yb:KLuW } & ZnO NRs & 139 & 9 & 0.2 & 190 & 790 & this work \\
\hline & graphene $(n=1)$ & 113 & 6 & 0.5 & 280 & 240 & {$[40]$} \\
\hline & graphene $(n=3)$ & 315 & 12 & 1.0 & 140 & 320 & [31] \\
\hline & $\mathrm{MoS}_{2}$ & 147 & 7 & 0.5 & 220 & 300 & [31] \\
\hline & SWCNTs & 633 & 17 & 1.1 & 80 & 602 & this work \\
\hline \multirow[t]{6}{*}{ Tm:KLuW } & ZnO NRs & 221 & 10 & 1.1 & 114 & 203 & this work \\
\hline & graphene $(n=1)$ & 310 & 13 & 1.6 & 285 & 190 & [22] \\
\hline & graphene $(n=3)$ & 1030 & 39 & 4.0 & 190 & 260 & [31] \\
\hline & $\mathrm{MoS}_{2}$ & 1270 & 43 & 7.5 & 175 & 170 & [31] \\
\hline & SWCNTs & 1360 & 41 & 5.5 & 48 & 250 & {$[41]$} \\
\hline & SESA & 539 & 21 & 1.1 & 61 & 498 & [41] \\
\hline
\end{tabular}

SWCNT-SAs, while the latter are less attractive since they are deposited in the form of a polymer thin film.

For the Tm laser, the best output characteristics are again achieved with the SWCNT-SA. The PQS performance of the $\mathrm{ZnO}$ NRs is better than other 2D materials (graphene-SA with a single carbon layer and few-layer $\mathrm{MoS}_{2}$ ) in terms of the pulse duration, similarly to the case of the $\mathrm{Yb}$ laser. This is attributed to the relatively large fraction of the saturable losses for the $\mathrm{ZnO}$ NRs, as summarized in Table 2.

$\mathrm{ZnO}$ nanocrystals (unoriented and with nearly-spherical shape) embedded in a polymer film have been previously applied as a $\mathrm{SA}$ only in $\mathrm{Er}$ and $\mathrm{Yb}$ fiber lasers. In the former case, the best pulse characteristics (duration/energy) were $3 \mu \mathrm{s} / 40 \mathrm{~nJ}$ corresponding to an output power of $\approx 3 \mathrm{~mW}$ at $1.561 \mu \mathrm{m}$ [26]. The $\mathrm{Yb}$ fiber laser PQS by $\mathrm{ZnO}$ nanocrystals generated $1.6 \mu \mathrm{s} / 3 \mathrm{~nJ}$ pulses at $1.039 \mu \mathrm{m}$ [42]. Thus, the present work, for the first time, demonstrates the ability of $\mathrm{ZnO}$ nanostructures to generate nanosecond pulses.

\section{Conclusion}

Hydrothermally grown hexagonal-shaped [001]-oriented $\mathrm{ZnO}$ NRs are a promising material for broadband saturable absorbers for near-IR lasers $(1-2 \mu \mathrm{m})$. In the present work, this has been verified by linear absorption measurements, the absorption saturation experiment at $\approx 1 \mu \mathrm{m}$ and the application of the $\mathrm{ZnO}$ NRs in diode-pumped $\mathrm{Yb}$ - and Tm-doped lasers. The $\mathrm{ZnO}$ NRs exhibit low saturation intensity (about $10 \mathrm{~kW} / \mathrm{cm}^{2}$ for ps pulses) which is two orders of magnitude lower than for $2 \mathrm{D}$ materials such as graphene and $\mathrm{MoS}_{2}$. The modulation depth of $\mathrm{ZnO}$ NRs can be easily adjusted by the growth duration.

The application of $\mathrm{ZnO}$ NRs as SAs in bulk $\mathrm{Yb}$ and Tm lasers indicated their capability to generate nanosecond pulses at high repetition rates up to the $\mathrm{MHz}$-range with $\mu \mathrm{J}$-level pulse energy.
The output characteristics of these lasers were limited by the scattering losses in ZnO NRs, which can be optimized by the synthesis method, for example, by additional annealing. Further improvement of the $\mathrm{ZnO}$ NR SA properties can follow two routes. First, the $\mathrm{ZnO}$ nanostructures can accommodate such transition-metal ions as $\mathrm{Mn}^{2+}$ or $\mathrm{Co}^{2+}$ in the $T_{\mathrm{d}}$ sites. This coordination is attractive for high ground-state transition crosssections, so that the absorption saturation in the visible and near-IR can be observed. Moreover, the dopant ions can promote the absorption saturation due to the defects in the $\mathrm{ZnO}$ structure.

Second, the ZnO NRs can be hydrothermally grown directly on the crystal surface. This technology is especially attractive for the PQS waveguide lasers relying on the evanescent field interaction with the SA deposited on top of the active layer/channel. Taking into account the excellent sensing properties of the $\mathrm{ZnO}$ NRs, such composite structures can be of interest for the development of bio-molecule and gas sensors based on pulsed waveguide lasers.

\section{Experimental \\ Growth of $\mathrm{ZnO}$ NRs}

$\mathrm{ZnO}$ NRs were directly grown on microscope glass slides (thickness: $1 \mathrm{~mm}$, double-side polished) using a hydrothermal process [43]. A $\mathrm{ZnO}$ seed layer was initially deposited on cleaned glass slides by spraying $5 \mathrm{mM}$ zinc acetate dehydrate solution in ethanol at $350{ }^{\circ} \mathrm{C}$. The role of this seed layer was to provide nucleation sites for the subsequent growth of $\mathrm{ZnO}$ NRs. The seeded substrates were then immerged in an aqueous solution of zinc nitrate hexahydrate $(10 \mathrm{mM})$ and hexamethylenetetramine $(10 \mathrm{mM})$ and the reaction bath was maintained at $90{ }^{\circ} \mathrm{C}$ for $5-15 \mathrm{~h}$. During the hydrothermal growth, the reaction solution was replenished every $5 \mathrm{~h}$ in order to maintain a constant growth rate of the NRs. Finally, the ZnO-NR-coated glass slides were rinsed thoroughly with deionized (DI) water and 
dried at $90{ }^{\circ} \mathrm{C}$ in an oven. The fabrication process is schematically illustrated in Figure 7. The samples with $\mathrm{ZnO}$ NRs were white in color.

\section{Characterization of the nanorods}

The morphology of the grown $\mathrm{ZnO}$ NRs was studied by field emission scanning electron microscopy (FESEM) using a JEOL JSM-7600F microscope. The structure of the grown ZnO NRs was studied by X-ray diffraction (XRD) using a Rigaku MiniFlex600 diffractometer. The XRD patterns of the samples were obtained using $\mathrm{Cu} \mathrm{K} \alpha$ radiation (1.5406 $\AA$ ) with diffraction angle from $20^{\circ}$ to $80^{\circ}$.

The vibrational properties of the NRs were studied by Raman spectroscopy using a XploRA confocal Raman microscope from Horiba. The Raman spectra were recorded using a $0.532 \mu \mathrm{m} \mathrm{CW}$ laser excitation with a $10 \times$ objective and 1800 lines/mm grating (spectral resolution better than $2 \mathrm{~cm}^{-1}$ ). An integration time of $30 \mathrm{~s}$ was used.

The absorption spectra were measured using a CARY 5000 spectrophotometer (Varian).

The absorption saturation of the $\mathrm{ZnO}$ NRs was studied by the open-aperture Z-scan method. As an excitation source, a modelocked $1.064 \mu \mathrm{m} \mathrm{Nd}$ laser was used with the following pulse characteristics: energy, $E=10 \mathrm{pJ}$ (the laser beam was attenuated), duration, $\Delta \tau=2 \mathrm{ps}$, and repetition frequency $58.15 \mathrm{MHz}$. The laser beam was focused to a spot size $2 w_{\mathrm{L}}$ of $92 \mu \mathrm{m}$ with a Rayleigh length of $6.23 \mathrm{~mm}$.

\section{Laser set-up}

As a gain material, monoclinic double tungstate crystals, $\mathrm{KLu}\left(\mathrm{WO}_{4}\right)_{2}$, doped with 3 atom $\% \mathrm{Yb}^{3+}(\mathrm{Yb}: \mathrm{KLuW})$ or 3 atom $\% \mathrm{Tm}^{3+}(\mathrm{Tm}: \mathrm{KLuW})$ were used. The crystals were grown by the top-seeded solution growth (TSSG) slow-cooling method. The laser elements were cut along the $N_{\mathrm{g}}$ axis of the optical indicatrix and were $3 \mathrm{~mm}$-thick and uncoated. These elements were pumped by a fiber-coupled laser diode (an InGaAs one, emitting at $\approx 0.978 \mu \mathrm{m}$, for the $\mathrm{Yb}$ laser, and an AlGaAs one, emitting at $\approx 0.802 \mu \mathrm{m}$, for the $\mathrm{Tm}$ laser). The polarization of the laser emission was linear, $\boldsymbol{E} \| N_{\mathrm{m}}$, naturally selected by the anisotropy of the gain. More details about the laser set-up can be found elsewhere [31].

\section{Acknowledgements}

This work was supported by Spanish Government (MAT201675716-C2-1-R, (AEI/FEDER, UE), TEC 2014-55948-R) and Generalitat de Catalunya (2014SGR1358). F.D. acknowledges additional support through the ICREA academia award 2010ICREA-02 for excellence in research. P.L. acknowledges financial support from the Government of the Russian Federation (Grant No. 074-U01) through ITMO Post-Doctoral Fellowship scheme.

\section{ORCID ${ }^{\circledR}$ iDs}

Pavel Loiko - https://orcid.org/0000-0002-4270-0668 Magdalena Aguiló - https://orcid.org/0000-0001-6130-9579 Francesc Díaz - https://orcid.org/0000-0003-4581-4967 Valentin Petrov - https://orcid.org/0000-0001-7247-6145

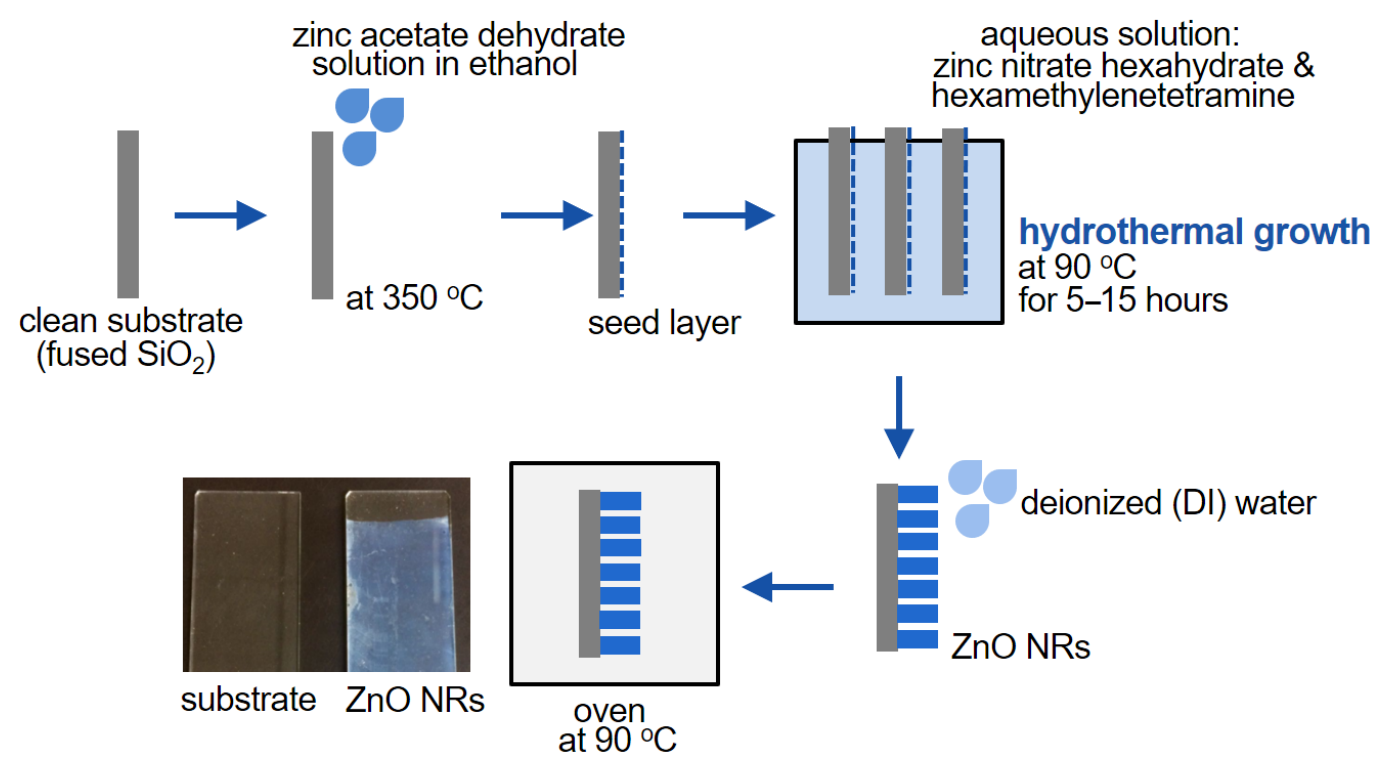

Figure 7: Schematic of the fabrication process of the ZnO NR saturable absorbers. 


\section{References}

1. Wang, Z. L. Appl. Phys. A: Mater. Sci. Process. 2007, 88, 7-15. doi:10.1007/s00339-007-3942-8

2. Willander, M.; Nur, O.; Zhao, Q. X.; Yang, L. L.; Lorenz, M.; Cao, B. Q.; Pérez, J. Z.; Czekalla, C.; Zimmermann, G.; Grundmann, M.; Bakin, A.; Behrends, A.; Al-Suleiman, M.; El-Shaer, A.; Mofor, A. C.; Postels, B.; Waag, A.; Boukos, N.; Travlos, A.; Kwack, H. S.; Guinard, J.; Dang, D. L. S. Nanotechnology 2009, 20, 332001. doi:10.1088/0957-4484/20/33/332001

3. Chichibu, S. F.; Sota, T.; Cantwell, G.; Eason, D. B.; Litton, C. W. J. Appl. Phys. 2002, 93, 756-758. doi:10.1063/1.1527707

4. Wang, Z. L. J. Phys.: Condens. Matter 2004, 16, R829-R858. doi:10.1088/0953-8984/16/25/R01

5. Baruah, S.; Dutta, J. Sci. Technol. Adv. Mater. 2009, 10, 013001. doi:10.1088/1468-6996/10/1/013001

6. Wei, A.; Pan, L.; Huang, W. Mater. Sci. Eng., B 2011, 176, 1409-1421. doi:10.1016/j.mseb.2011.09.005

7. Niyuki, R.; Fujiwara, H.; Nakamura, T.; Ishikawa, Y.; Koshizaki, N.; Tsuji, T.; Sasaki, K. APL Photonics 2017, 2, 036101. doi:10.1063/1.4974334

8. Zhang, Q.; Dandeneau, C. S.; Zhou, X.; Cao, G. Adv. Mater. 2009, 21, 4087-4108. doi:10.1002/adma.200803827

9. Janotti, A.; Van de Walle, C. G. Phys. Rev. B 2007, 76, 165202. doi:10.1103/PhysRevB.76.165202

10. Oba, F.; Togo, A.; Tanaka, I.; Paier, J.; Kresse, G. Phys. Rev. B 2008, 77, 245202. doi:10.1103/PhysRevB.77.245202

11. Djurišić, A. B.; Leung, Y. H.; Tam, K. H.; Ding, L.; Ge, W. K.; Chen, H. Y.; Gwo, S. Appl. Phys. Lett. 2006, 88, 103107. doi:10.1063/1.2182096

12. Bao, Q.; Zhang, H.; Wang, Y.; Ni, Z.; Yan, Y.; Shen, Z. X.; Loh, K. P.; Tang, D. Y. Adv. Funct. Mater. 2009, 19, 3077-3083. doi:10.1002/adfm.200901007

13. Cho, W. B.; Yim, J. H.; Choi, S. Y.; Lee, S.; Schmidt, A.; Steinmeyer, G.; Griebner, U.; Petrov, V.; Yeom, D.-I.; Kim, K.; Rotermund, F. Adv. Funct. Mater. 2010, 20, 1937-1943. doi:10.1002/adfm.200902368

14. Sobon, G.; Sotor, J.; Jagiello, J.; Kozinski, R.; Zdrojek, M.; Holdynski, M.; Paletko, P.; Boguslawski, J.; Lipinska, L.; Abramski, K. M. Opt. Express 2012, 20, 19463-19473. doi:10.1364/OE.20.019463

15. Lin, G.-R.; Lin, Y.-C. Laser Phys. Lett. 2011, 8, 880-886. doi:10.1002/lapl.201110078

16. Wang, S.; Yu, H.; Zhang, H.; Wang, A.; Zhao, M.; Chen, Y.; Mei, L.; Wang, J. Adv. Mater. 2014, 26, 3538-3544. doi:10.1002/adma.201306322

17. Wu, K.; Zhang, X.; Wang, J.; Li, X.; Chen, J. Opt. Express 2015, 23, 11453-11461. doi:10.1364/OE.23.011453

18. Lu, S. B.; Miao, L. L.; Guo, Z. N.; Qi, X.; Zhao, C. J.; Zhang, H.; Wen, S. C.; Tang, D. Y.; Fan, D. Y. Opt. Express 2015, 23, 11183-11194. doi:10.1364/OE.23.011183

19. Zhao, C.; Zhang, H.; Qi, X.; Chen, Y.; Wang, Z.; Wen, S.; Tang, D. Appl. Phys. Lett. 2012, 101, 211106. doi:10.1063/1.4767919

20. Loiko, P.; Bogusławski, J.; Serres, J. M.; Kifle, E.; Kowalczyk, M.; Mateos, X.; Sotor, J.; Zybała, R.; Mars, K.; Mikuła, A.; Kaszyca, K.; Aguiló, M.; Díaz, F.; Griebner, U.; Petrov, V. Opt. Mater. Express 2018, 8, 1723-1732. doi:10.1364/OME.8.001723

21. Fan, M.; Li, T.; Li, G.; Ma, H.; Zhao, S.; Yang, K.; Kränkel, C. Opt. Lett. 2017, 42, 286-289. doi:10.1364/OL.42.000286
22. Serres, J. M.; Loiko, P.; Mateos, X.; Yumashev, K.; Griebner, U.; Petrov, V.; Aguiló, M.; Díaz, F. Opt. Express 2015, 23, 14108-14113. doi:10.1364/OE.23.014108

23. Singh, A.; Kumar, S.; Das, R.; Sahoo, P. K. RSC Adv. 2015, 5, 88767-88772. doi:10.1039/C5RA15386G

24. Lee, H. W.; Lee, K. M.; Lee, S.; Koh, K. H.; Park, J.-Y.; Kim, K.; Rotermund, F. Chem. Phys. Lett. 2007, 447, 86-90. doi:10.1016/j.cplett.2007.08.086

25. Zhu, Y.; Elim, H. I.; Foo, Y.-L.; Yu, T.; Liu, Y.; Ji, W.; Lee, J.-Y.; Shen, Z.; Wee, A. T. S.; Thong, J. T. L.; Sow, C. H. Adv. Mater. 2006, 18, 587-592. doi:10.1002/adma.200501918

26. Ahmad, H.; Lee, C. S. J.; Ismail, M. A.; Ali, Z. A.; Reduan, S. A.; Ruslan, N. E.; Ismail, M. F.; Harun, S. W. Opt. Commun. 2016, 381 , 72-76. doi:10.1016/j.optcom.2016.06.073

27. Loiko, P. A.; Dymshits, O. S.; Vitkin, V. V.; Skoptsov, N. A.; Zhilin, A. A.; Shemchuk, D. V.; Tsenter, M. Y.; Bogdanov, K. V.; Malyarevich, A. M.; Glazunov, I. V.; Mateos, X.; Yumashev, K. V. Laser Phys. Lett. 2016, 13, 055803. doi:10.1088/1612-2011/13/5/055803

28. Loiko, P.; Bora, T.; Serres, J. M.; Mateos, X.; Yu, H.; Baranov, A.; Aguiló, M.; Díaz, F.; Griebner, U.; Petrov, V.; Dutta, J. Oriented ZnO nanorods: A novel saturable absorber for lasers at 1-2 $\mu \mathrm{m}$. In Proceedings of the Conference on Lasers and Electro-Optics Europe \& European Quantum Electronics Conference (CLEO/Europe-EQEC), Munich, Germany, June 25-29, 2017; Cerullo, G.; Pruneri, V., Eds.; IEEE, 2017. doi:10.1109/CLEOE-EQEC.2017.8086630

29. Zhang, R.; Yin, P.-G.; Wang, N.; Guo, L. Solid State Sci. 2009, 11, 865-869. doi:10.1016/j.solidstatesciences.2008.10.016

30. Wang, K.; Wang, J.; Fan, J.; Lotya, M.; O'Neill, A.; Fox, D.; Feng, Y.; Zhang, X.; Jiang, B.; Zhao, Q.; Zhang, H.; Coleman, J. N.; Zhang, L.; Blau, W. J. ACS Nano 2013, 7, 9260-9267. doi:10.1021/nn403886t

31. Serres, J. M.; Loiko, P.; Mateos, X.; Yu, H.; Zhang, H.; Chen, Y.; Petrov, V.; Griebner, U.; Yumashev, K.; Aguiló, M.; Díaz, F. Opt. Mater. Express 2016, 6, 3262-3273. doi:10.1364/OME.6.003262

32. Loiko, P.; Mateos, X.; Choi, S. Y.; Rottermund, F.; Serres, J. M.; Aguiló, M.; Díaz, F.; Yumashev, K.; Griebner, U.; Petrov, V. J. Opt. Soc. Am. B 2016, 33, D19-D27. doi:10.1364/JOSAB.33.000D19

33. Wang, X. J.; Vlasenko, L. S.; Pearton, S. J.; Chen, W. M.; Buyanova, I. A. J. Phys. D: Appl. Phys. 2009, 42, 175411. doi:10.1088/0022-3727/42/17/175411

34. Erhart, P.; Albe, K.; Klein, A. Phys. Rev. B 2006, 73, 205203. doi:10.1103/PhysRevB.73.205203

35. Kang, D.; Liu, A.; Bian, J.; Sang, Y. ECS Solid State Lett. 2012, 1, P15-P17. doi:10.1149/2.007201ssl

36. van Dijken, A.; Meulenkamp, E. A.; Vanmaekelbergh, D.; Meijerink, A. J. Lumin. 2000, 90, 123-128. doi:10.1016/S0022-2313(99)00599-2

37. Vanheusden, K.; Warren, W. L.; Seager, C. H.; Tallant, D. R.; Voigt, J. A.; Gnade, B. E. J. Appl. Phys. 1996, 79, 7983-7990. doi:10.1063/1.362349

38. Ye, J. D.; Gu, S. L.; Qin, F.; Zhu, S. M.; Liu, S. M.; Zhou, X.; Liu, W.; Hu, L. Q.; Zhang, R.; Shi, Y.; Zheng, Y. D. Appl. Phys. A: Mater. Sci. Process. 2005, 81, 759-762. doi:10.1007/s00339-004-2996-0

39. Yasukevich, A. S.; Loiko, P.; Gusakova, N. V.; Serres, J. M.; Mateos, X.; Yumashev, K. V.; Kuleshov, N. V.; Petrov, V.; Griebner, U.; Aguiló, M.; Díaz, F. Opt. Commun. 2017, 389, 15-22. doi:10.1016/j.optcom.2016.12.023 
40. Loiko, P. A.; Serres, J. M.; Mateos, X.; Liu, J.; Zhang, H.; Yasukevich, A. S.; Yumashev, K. V.; Petrov, V.; Griebner, U.; Aguiló, M.; Díaz, F. Appl. Phys. B: Lasers Opt. 2016, 122, 105. doi:10.1007/s00340-016-6384-1

41. Mateos, X.; Loiko, P.; Choi, S. Y.; Rotermund, F.; Aguiló, M.; Díaz, F.; Griebner, U.; Petrov, V. Laser Phys. Lett. 2017, 14, 095801. doi:10.1088/1612-202X/aa7f17

42. Ahmad, H.; Salim, M. A. M.; Ismail, M. F.; Harun, S. W. Laser Phys. 2016, 26, 115107. doi:10.1088/1054-660X/26/11/115107

43. Bora, T.; Zoepfl, D.; Dutta, J. Sci. Rep. 2016, 6, 26913. doi:10.1038/srep26913

\section{License and Terms}

This is an Open Access article under the terms of the Creative Commons Attribution License

(http://creativecommons.org/licenses/by/4.0). Please note that the reuse, redistribution and reproduction in particular requires that the authors and source are credited.

The license is subject to the Beilstein Journal of

Nanotechnology terms and conditions:

(https://www.beilstein-journals.org/bjnano)

The definitive version of this article is the electronic one which can be found at: doi:10.3762/bjnano.9.255 